\title{
Selected issues of control voltage source inverter with self- excited synchronous generator as DC grid voltage source
}

\author{
Maciej $\operatorname{Kozak}^{1, *}$ \\ ${ }^{1}$ Maritime University of Szczecin, Institute of Marine Automation and Electrotechnics, 70-500 Szczecin, Poland
}

\begin{abstract}
Synchronous self-excited generators are the most popular AC voltage sources installed in power plants of seagoing vessels. Because of fuel savings varying revolutions Diesel drives can be found on selected types of ships (platform support vessels, cable layers, tug boats etc.). Very interesting issue is use of such type of alternator working with inverter acting as rectifier in direct current grid system. In direct current type of electrical grid the problems with synchronization and reactive power balance are absent. As the control method most suitable to use is modified version of field oriented control (FOC) known from induction machines. Aforementioned method involves decoupling of currents and control voltages to flux and torque components and keeping them in the most optimal condition. Theoretical background of inverter and synchronous generator adopted FOC control method along with numerical situations and experimental results obtained in laboratory test bench of such a system were included in following article.
\end{abstract}

\section{Introduction to synchronous generator control method}

The classical approach of the synchronous generators control with independent exciting winding is the active and reactive power control by means of the voltage and frequency adjustment [1]. In the most cases the two control loops are operating separately each to others with use of RPM's governor and voltage regulator. This kind of operation may be considered as a scalar control procedure, which disregards some phenomena, i.e. the coupling effect between electrical axis the synchronous generator [2]. The vector control is based on the fieldorientation principle. It can be used as an $\mathrm{AC}$ induction motor drives control, but also for squirrel cage generator running. Because of its performance during transient operation modes, it comes quite close to direct current machines. The mathematical background of the dynamic model and vector control of AC machine is given by the space-phasor theory [2], [4]. The rotor flux oriented synchronous machine model is similar to a shunt excited direct current machine. It is suitable for the simulation of the synchronous generator operation, but the control will be realized with the field oriented model considering the resultant stator flux. This model leads to the analogy with the compensated DC machine, which allows the independent control of the two variables that produce the machine torque [2], [3], [4], [5]. In Fig. 1 there are shown the stator field oriented components of the stator current:

$$
i_{s}=i_{s d \lambda}+\mathrm{j} i_{s q \lambda}
$$

while the armature coil flux equals to:

$$
\Psi_{s s}=\Psi_{s s d \lambda s}+\mathrm{j} \Psi_{s s q \lambda s}=L_{m d} i_{s d \lambda}+\mathrm{j} L_{m q} i_{s q \lambda}
$$

where $\lambda_{s}$ is the angular position of the resultant stator flux $\Psi_{s}$.

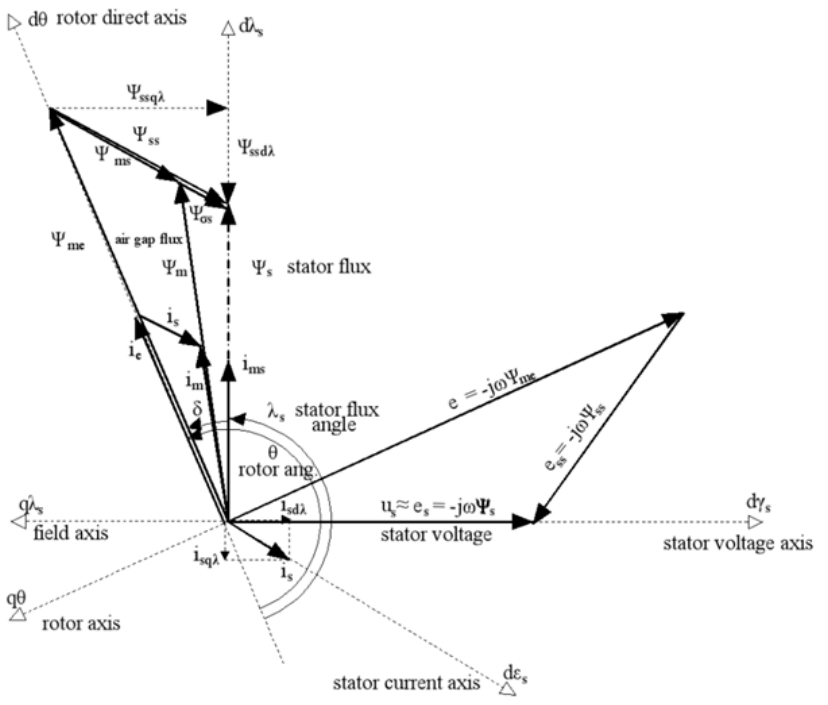

Fig. 1. Diagram of the synchronous generator with leading stator current, and the stator-field oriented space phasors of the stator current [2].

In the generating mode, the quadrature component of the armature flux $\Psi_{s s d \lambda}$, which determines the active power and DC intermediate circuit voltage will be negative due to the reversed active energy flow. Flux denoted as $\Psi_{s s q \lambda}$ is also negative, due to its demagnetizing character. This flux corresponds to the reactive power produced by alternator and covering the reactive load.

\footnotetext{
Corresponding author:m.kozak@am.szczecin.pl
} 


\subsection{Self-excited synchronous generator FOC control properties}

In order to have a full control for generator some simplification has been taken into consideration regarding the produced torque. The load torque coming from PI regulator in outer DC voltage control loop can be regulated by controlling the generators torque angle. In the constant torque angle control strategy, the $d$ axis current is kept at zero value for all of the operation time, while the vector current is aligned with the $\mathrm{q}$ axis in order to maintain the torque angle equal close to $90^{\circ}$. The torque equation for a synchronous alternator, taking into account both $i_{\text {sd }}$ and $i_{\text {sq }}$ currents is the one derived in:

$$
T_{e}=\frac{3}{2} \mathrm{p}\left[\Psi_{m} i_{s q}+\left(L_{d}-L_{q}\right) i_{s q} i_{s d}\right]
$$

where: $p$ is a number of pole pairs and $\psi_{m}$ is field winding flux. After substituting the $\mathrm{d}-\mathrm{q}$ currents in equation (3) and after a few simplifications the torque value is the one presented in equation (4).

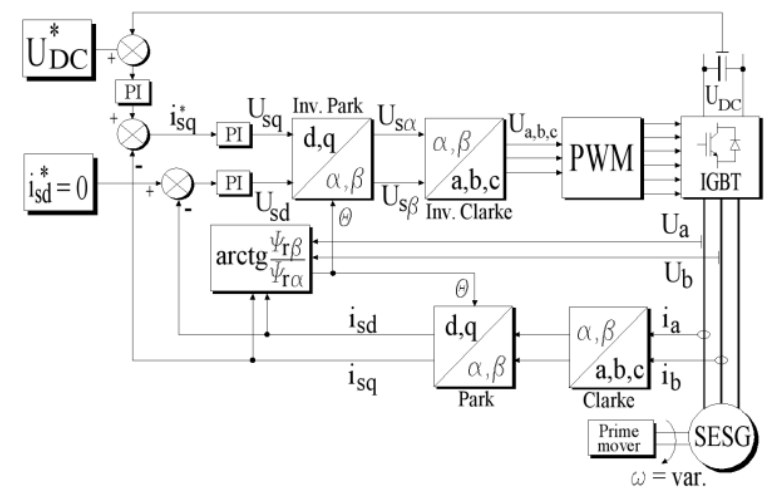

Fig. 2. Vector control structure of the self-excited synchronous generator with stator-field orientation.

$$
T_{e}=\frac{3}{2} \mathrm{p} \Psi_{m} i_{s q}
$$

From above equation it can be easily observed that the control property is very simple to implement, just by representing the linearization between the torque and machine active current.

\section{Test bench and experimental results}

To fully test presented system laboratory setup was prepared. The test bench consists of synchronous generator driven by electric motor. Terminals of generator are connected to the 3-phase inverter controlled by real time operating DSP-FPGA board. Control method used was sensorless technique which omits encoder and rotor angle was calculated from measured currents and Clarke transformation. As the load the resistor connected to the DC intermediate circuit was used. System was equipped also with another generator powered inverter that produced DC voltage and was used to prove robustness of power sharing algorithm.

While in so called island operation synchronous generator worked in the principle of maintaining constant DC voltage on inverter's intermediate circuit capacitors for wide range of rotational speeds.

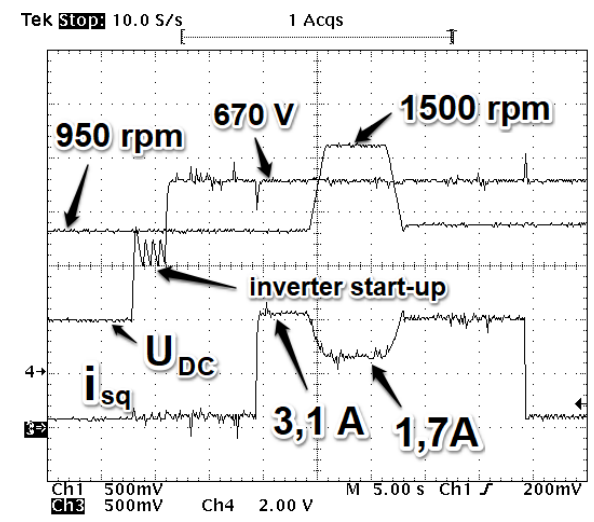

Fig. 3. Experimental results of start-up, load apply and speed change under load of synchronous generator-inverter set.

While inverter startup procedure different set of PI regulators coefficients was used to proper compensation of changing with speed electromotive force what can be clearly seen in some $U_{D C}$ oscillations. Presented system has also possibility to work in parallel power sharing mode along with other DC current controlled sources with use of auctioneering diodes.

\section{Conclusions and further work}

As it was proven in laboratory test bench proposed system is very stable and DC voltage variations does not exceed $5 \%$ in steady state and $10 \%$ in transient operation in both island and power sharing mode. Further work will focus on integrating ultracapacitors with controlled DC-DC converter to presented system. Thanks to its properties, the system will be further developed towards further optimization and easy integration with existing solutions.

\section{References}

[1] Z. Qing-Chang, Z. Yu, Parallel Operation of Inverters with Different Types of Output Impedance, Industrial Electronics Society, IECON 2013 - 39th Annual Conference of the IEEE

[2] M. Imecs, I. Iov Incze, C. Szabo, Stator-Field Oriented Control of the Synchronous Generator: Numerical Simulation, 2008 International Conference on Intelligent Engineering Systems, ISSN 1543-9259, 2008 [3] M. Kozak , A. Bejger, R. Gordon, Zeszyty Naukowe Akademii Morskiej w Szczecinie 45, 17-22, 2016

[4] S. A. Baktyono, Study of Field-Oriented Control of a Permanent Magnet Synchronous Generator and Hysteresis Current Control for Wind Turbine Application, The Ohio State University, 2006

[5] R. Balog,, P.T. Krein, IEEE Transactions on Power Electronics 26/3, 860-867 (2011) 